\title{
DOCUMENTOS
}

\section{Karl Marx sobre la dictadura del proletariado y la revolución en permanencia. Dos documentos del año 1850}

\author{
Editados y traducidos por \\ Manuel Quiroga y Daniel Gaido \\ (UNC y UNC-Conicet)
}

Los primeros usos documentados por parte de Marx de la expresión "dictadura del proletariado" (una consigna no incluida en el Manifiesto comunista) corresponden al año 1850 y son los siguientes:

- Karl Marx, "Las luchas de clases en Francia, 1848-1850" (enero-marzo 1850).

- Règlement de la Société Universelle des Communistes Révolutionnaires (abril 1850).

- Declaración a la Neue Deutsche Zeitung n ${ }^{\circ} 158$ (25 de junio de 1850).

En esta edición incluimos versiones españolas de los últimos dos documentos, traducidos de los originales en francés y alemán. Es interesante constatar que, en los tres casos antes mencionados, Marx utiliza la expresión "dictadura del proletariado" junto con la de "revolución en permanencia" -una estrategia sistematizada en el "Mensaje del Comité Central a la Liga de los Comunistas", escrito por Marx y Engels a fines de marzo de 1850 (Marx y Engels, 1850) con la intención de expresar las conclusiones politicas que ambos creían necesario extraer de la experiencia de las revoluciones de 1848-. En el primer momento de ese proceso revolucionario, la acción política de Marx y Engels en Alemania se había desarrollado como parte del ala izquierda de las organizaciones democráticas. ${ }^{1}$ Esta estrategia incluso se había delineado en la primera

1. Engels explica su posición durante la revolución: “...nuestra bandera, al fundar en Alemania un gran periódico, no podía ser otra que la bandera de la democracia [...]. Si no hubiéramos procedido de este modo, $[. .$.$] no nos hubiera quedado más remedio$ 
versión del Manifiesto comunista: "En Alemania, el Partido Comunista lucha al lado de la burguesía, en tanto que ésta actúa revolucionariamente contra la monarquía absoluta, la propiedad territorial feudal y la pequeña burguesía reaccionaria" (Marx y Engels, 1848: 140). Sin embargo, la actitud de la burguesía (y de su órgano político, el parlamento de Frankfurt) durante la revolución hizo desaparecer cualquier expectativa de que ésta pudiera llegar a tener una conducta similar a la de la burguesía francesa en 1789. En diciembre de 1848 Marx escribió:

La burguesía alemana se había desarrollado con tanta languidez, tan cobardemente y con tal lentitud, que, en el momento en que se opuso amenazadora al feudalismo y al absolutismo, se encontró con la amenazadora oposición del proletariado y de todas las capas de la población urbana cuyos intereses e ideas eran afines a los del proletariado. Y se vio hostilizada no sólo por la clase que estaba detrás, sino por toda la Europa que estaba delante de ella. La burguesía prusiana no era, como la burguesía francesa de 1789 , la clase que representaba a toda la sociedad moderna frente a los representantes de la vieja sociedad: la monarquía y la nobleza. [...] inclinada desde el primer instante a traicionar al pueblo y a pactar un compromiso con los representantes coronados de la vieja sociedad [...] tal era la burguesía prusiana cuando, después de marzo, se encontró al timón del estado prusiano. (Marx, 1848: 143)

Por otro lado, fuera de Alemania, la represión que el gobierno francés surgido de la revolución de febrero había desatado sobre el proletariado parisino en las jornadas de junio del 48 también impactó en el análisis de Marx a nivel continental. ${ }^{2}$

Al finalizar la revolución, el balance sobre la actitud de la burguesía como clase y de las organizaciones democráticas como tales, llevaron a Marx y Engels a buscar un nuevo programa que distinguiera radicalmente las organizaciones obreras de la "democracia" en general. Es

que ponernos a predicar el comunismo en alguna hojita lugareña y fundar, en vez de un gran partido de acción, una pequeña secta" (Engels, 1884a: 1176-1177). Las fuentes para la historia de la Liga de los Comunistas fueron reunidas en tres volúmenes (Hundt et al., 1970-1984). La historia más detallada es la de Martin Hundt, solo disponible en alemán (Hundt, 1993).

2. "El proletariado de París fue obligado por la burguesía a hacer la insurrección de Junio.... Y sus reivindicaciones, desmesuradas en cuanto a la forma, pero minúsculas e incluso todavia burguesas por su contenido, cuya satisfacción quería arrancar a la república de Febrero, cedieron el puesto a la consigna audaz y revolucionaria: ¡Derrocamiento de la burguesía! ¡Dictadura de la clase obrera!” (Marx, 1850a: 231). 
en este marco donde surgen los nuevos conceptos programáticos de la dictadura del proletariado y la permanencia de la revolución, unidos a la intención política de "trazar una línea divisoria tanto ideológica como organizacional entre los exiliados socialistas y los no socialistas" -en otras palabras, de separar a los comunistas de los demócratas pequeñoburgueses (Lattek, 2006: 56)-.. ${ }^{3}$ Este planteo aparece expresado en "Mensaje del Comité Central a la Liga de los Comunistas" (marzo de 1850) y fue una de las razones principales que llevaron a Marx y Engels a intentar fundar una corriente obrera internacional, que se expresa en el primero de los documentos aquí presentados.

El "Reglamento de la sociedad universal de los comunistas revolucionarios" fue un acuerdo programático firmado por dos refugiados blanquistas en Londres, Louis Adam y Jules Vidil, en representación de la Société des proscrits dèmocrates socialistes; por August Willich, Karl Marx y Friedrich Engels en representación del Bund der Kommunisten (Liga de los Comunistas); y por George Julian Harney, el director de The Northern Star, la publicación central del movimiento cartista. Este documento intentó ser la base programática que permitiera la unificación de las principales corrientes comunistas dentro del movimiento obrero europeo. Por supuesto, no todas estas corrientes tenian posiciones claramente comunistas ni clasistas desde antes: la expresión "última forma de constitución de la familia humana" en el "Reglamento" no corresponde a la terminología marxista, como tampoco "el principio de la fraternidad republicana"; ambas expresiones fueron concesiones hechas por Marx y Engels a los blanquistas. ${ }^{4}$

Lattek explica cómo continuó el intento de establecer la organización tras el primer acuerdo programático: "El 6 de mayo de 1850, sólo unas pocas semanas después de la fundación de la Sociedad Universal de los comunistas revolucionarios, Marx y Engels escribieron a François

3. Ver también Lattek, 2006: 46: "A principios de 1850 la línea divisoria había sido trazada, por lo tanto, entre los exiliados democráticos y los socialistas. Cada grupo tenía su propio club, su comité de asistencia, y, durante un tiempo, su propio periódico, agrupándose en torno al Deutsche Londoner Zeitung o bien a la Neue Rheinische Zeitung-politisch-ökonomische Revue de Marx. A pesar de los desacuerdos y los conflictos que pronto estallarían dentro de cada campo, se entendió que a partir de ahora la principal línea divisoria era la que separaba a los veteranos de la revolución del "48 socialistas y no socialistas".

4. Siete copias del documento, firmadas de puño y letra por los signatarios, fueron producidas. El documento fue descubierto y publicado por primera vez por David Riazanov en 1928, en un artículo titulado "Sobre la cuestión de la relación entre Marx y Blanqui” (Riazanov, 1928). En una carta a Louis-Auguste Blanqui del año 1861, Marx lo llama "la cabeza y el corazón del partido proletario en Francia" (Bernstein, 1975: 391). 
Pardigon, secretario de la Société des proscrits dèmocrates socialistes blanquista en Londres, a su dirección en Rathbone Place, advirtiéndole en contra de una colaboración prevista con los demócratas alemanes en Greek Street [una referencia al Club Democrático alemán creado en Londres en abril de 1850 y situado en 22 Greek Street] y amenazando con cortar todos los lazos con la sociedad francesa, si esto ocurriera. Es evidente, por lo tanto, que la unión de Marx y Engels con los blanquistas efectivamente descansaba en un frente común contra los demócratas no-socialistas, y se convirtió en no válida en el momento en que esta alianza fue abandonada por los propios blanquistas" (Lattek, 2006: 56).

Este análisis coincide con las declaraciones del propio Marx, contenidas en una carta enviada a Engels el 13 de julio de 1851, acerca del famoso "Mensaje del Comité Central a la Liga de los Comunistas" de marzo de 1850: "El Mensaje a la Liga que escribimos conjuntamente [no era] en el fondo [sino] un plan de campaña contra la democracia". ${ }^{5}$ En el mismo sentido se pronunció Engels en su Contribución a la Historia de la Liga de los Comunistas: "El Mensaje, redactado por Marx y por mí, tiene todavía hoy interés, pues la democracia pequeñoburguesa sigue siendo aún el partido que en la próxima conmoción europea, que no tardará en producirse [...], será, necesariamente, el primero en empuñar el timón de Alemania, como salvador de la sociedad frente a los obreros comunistas" (Engels, 1885: 198).

Este -en palabras de Fernando Claudin- "primer intento de «Internacional Comunista" fue efimero: duró aproximadamente desde abril hasta octubre de 1850 (Claudín, 1985: 229). Lo que terminó de asestar el golpe mortal a la Sociedad universal de los comunistas revolucionarios, además del acercamiento de los refugiados blanquistas en Londres a los exiliados demócratas "progresistas" alemanes, fue la escisión en el seno de la Liga de los Comunistas el 15 de septiembre de 1850, entre el ala liderada por Marx y Engels y la tendencia dirigida por el grupo Willich-Schapper. De este modo, las dificiles condiciones politicas prevalecientes en Europa tras la derrota de las revoluciones del 48 hicieron abortar el desarrollo de una organización proletaria internacional. Una idea semejante tendría éxito recién en 1864 con la fundación de la Asociación Internacional de los Trabajadores, en condiciones políticas muy diferentes. El documento fundacional de la Sociedad Universal de los Comunistas Revolucionarios es importante tanto por haber intentado expresar una nueva orientación programática para las organizaciones

5. "Dies die von uns beiden verfasste 'Ansprache an den Bund' - au fond nichts als ein Kriegsplan gegen die Demokratie” (Marx y Engels, 1965: 278). 
proletarias de Europa, como por haber sido un primer intento de conformar una internacional obrera.

El segundo documento seleccionado es la declaración de Karl Marx y Friedrich Engels contra Otto Lüning, publicada en Frankfurt el 4 de julio de 1850. Otto Lüning (1818-1868), un representante del "socialismo verdadero" alemán, fue un político westfaliano, periodista y médico de los pobres, y por un tiempo miembro de la Liga de los Comunistas. Desde 1840 a 1850 trabajó en Rheda como médico, cirujano y obstetra. De 1845 a 1848 fue editor del periódico Das Westphälische Dampfboot. Entre 1848 y 1850, junto con su cuñado Joseph Weydemeyer, Lüning fue editor del periódico Neue Deutschen Zeitung, que era el órgano oficial de los diputados de izquierda de la Asamblea Nacional de Frankfurt. Tras la disolución de la Asamblea Nacional por las tropas prusianas, Lüning huyó a Suiza, donde vivió en Zurich hasta que su esposa murió en 1856. Luego regresó a Rheda, donde tomó nuevamente posesión de su cargo como médico. Desde 1862 hasta 1867 Lüning fue representante de una circunscripción de Berlín en la Cámara de Diputados de Prusia. Fue al principio miembro del Partido Progresista Alemán, y luego de su escisión en 1866 pasó a apoyar a los Nacional Liberales que secundaban la política de Bismarck. A partir de 1864, Lüning fue también editor del periódico Westfälischen Zeitung en Dortmund.

El motivo de la declaración de Marx fue una reseña que hizo Lüning en la Neue Deutsche Zeitung [Nueva gaceta alemana], $\mathrm{n}^{\circ} 148-151$, del $22,23,25$ y 26 junio de 1850 , de los cuatro números publicados hasta entonces de la revista editada por Marx y Engels, Neue Rheinische Zeitung. Politisch-ökonomische Revue, y en especial de las obras Las luchas de clases en Francia de 1848 a 1850, de Marx y "La campaña por la constitución alemana", de Engels. En su declaración, Marx se opuso a la distorsión que hacía Lüning de su teoría de la dictadura del proletariado y de la abolición de las distinciones de clase, mientras que Engels, en una declaración adjunta, defendió su evaluación de la Neue Rheinische Zeitung, según la cual éste fue el único órgano de prensa que, durante la revolución alemana de 1848/49, representó consecuentemente la posición revolucionaria del proletariado.

Es interesante constatar que el cuñado y co-editor de Lüning, Joseph Weydemeyer (quien después del aplastamiento de la revolución alemana emigró a los Estados Unidos, llegando a Nueva York el 7 de noviembre de 1851), publicó el 1 de enero 1852 un artículo en la revista New York Turn-Zeitung titulado "La dictadura del proletariado", defendiendo las concepciones de Marx (Weydemeyer, 1852). Es a este mismo Weydemeyer a quien Marx escribiría un par de años más tarde una famosa carta, que constituye su cuarta y más detallada referencia a la dictatura del proletariado: 
Por lo que a mí se refiere, no me cabe el mérito de haber descubierto la existencia de las clases en la sociedad moderna ni la lucha entre ellas. Mucho antes que yo, algunos historiadores burgueses habian expuesto ya el desarrollo histórico de esta lucha de clases y algunos economistas burgueses la anatomía económica de éstas. Lo que yo he aportado de nuevo ha sido demostrar: 1) que la existencia de las clases sólo va unida a determinadas fases históricas de desarrollo de la producción; 2) que la lucha de clases conduce, necesariamente, a la dictadura del proletariado; 3) que esta misma dictadura no es de por sí más que el tránsito hacia la abolición de todas las clases y hacia una sociedad sin clases. (Marx, 1852)

$* * *$

\section{Reglamento de la sociedad universal de los comunistas revolucionarios (abril de 1850)}

Fuente: "Règlement de la Société Universelle des Communistes Révolutionnaires" (en Marx y Engels, 1977: 568.)

Artículo primero: El objetivo de la asociación es el derrocamiento de todas las clases privilegiadas, el sometimiento de dichas clases a la dictadura del proletariado, manteniendo la revolución en permanencia hasta la realización del comunismo, que será la última forma de constitución de la familia humana.

Art. 2. Para contribuir a la realización de dicho objetivo, la asociación formará lazos de solidaridad entre todas las fracciones del partido comunista revolucionario, haciendo desaparecer, conforme al principio de la fraternidad republicana, las divisiones de nacionalidad.

Art. 3. El Comité fundador de la asociación se ha constituido en comité central; él establecerá, en todos los lugares donde sea necesario para el logro de su obra, los comités que mantendrán correspondencia con el comité central.

Art. 4. El número de miembros de la asociación es ilimitado, mas ningún miembro podrá ser admitido si no ha reunido un voto unánime. En ningún caso la elección podrá tener lugar mediante el escrutinio secreto.

Art. 5. Todos los miembros de la asociación se comprometen por juramento a mantenerse dentro de los términos absolutos del primer artículo del presente reglamento. Una modificación que pueda tener como consecuencia el debilitamiento de las intenciones expresadas en el artículo primero libera a los miembros de la asociación de su compromiso. 
Art. 6. Todas las decisiones de la sociedad son tomadas por la mayoría de dos tercios de los votantes.

$$
* * \star
$$

\title{
Declaración de Karl Marx al editor de la revista Neue Deutsche Zeitung [Otto Lüning] (4 de julio de 1850)
}

\author{
Fuente: "Erklärung an den Redakteur der Neue Deutsche Zeitung", \\ $\mathrm{n}^{\mathrm{o}} 158$ del 4 de julio de 1850 (en Marx y Engels, 1973: 323-324.)
}

\section{Al editor de la Neue Deutsche Zeitung:}

Usted me ha reprochado en las páginas de vuestro periódico, el 22 de junio de 1850, que defendiera el gobierno [die Herrschaft: la dominación] y la dictadura de la clase obrera, mientras que usted, por el contrario, aboga por la abolición de las distinciones de clase en general. No entiendo esta corrección.

Usted sabe muy bien que el Manifiesto del Partido Comunista (publicado antes de la revolución de febrero de 1848), dice en p. 16: "Cuando en la lucha contra la burguesía el proletariado se constituye necesariamente en clase; cuando mediante la revolución se convierte en clase dominante y, en cuanto clase dominante, suprime por la fuerza las viejas relaciones de producción, suprime, al mismo tiempo que estas relaciones de producción, las condiciones para la existencia de los antagonismos de clase y de las clases en general, y, por lo tanto, su propia dominación como clase".

Usted sabe que he defendido la misma opinión en mi libro Miseria de la filosofia contra Proudhon, [una obra publicada] antes de febrero de $1848 .^{6}$

Por último, se dice en el propio ensayo que critica, número 3 , p. 32

6. Marx hace referencia a este pasaje de su libro Miseria de la filosofia:

“¿Esto quiere decir que después del derrocamiento de la vieja sociedad sobrevendrá una nueva dominación de clase, que culminará en un nuevo poder político? No.

La condición de la emancipación de la clase obrera es la abolición de todas las clases, del mismo modo que la condición de la emancipación del tercer estado, del orden burgués, fue la abolición de todos los estados (del antiguo régimen) y de todos los órdenes.

En el transcurso de su desarrollo, la clase obrera sustituirá la antigua sociedad civil por una asociación que excluya a las clases y su antagonismo, y no existirá ya un poder político propiamente dicho, pues el poder político es precisamente la expresión oficial del antagonismo dentro de la sociedad civil." (Marx 1847, p. 121.)] 
de la Neue Rheinische Zeitung [Nueva gaceta renana]: "Este socialismo (es decir, el comunismo) es la declaración de la permanencia de la revolución, de la dictadura de clase del proletariado como punto necesario de transición para la abolición de las diferencias de clase en general, para la supresión de todas las relaciones de producción en las que éstas descansan, para la supresión de todas las relaciones sociales que corresponden a esas relaciones de producción, para la subversión de todas las ideas que brotan de estas relaciones sociales." (Marx, 1850a: 288.)

Karl Marx, 25 de junio de 1850

\section{Referencias}

Claudín, Fernando (1985), Marx, Engels y la revolución de 1848, Madrid: Siglo XXI.

Bernstein, Samuel (1975), Blanqui y el blanquismo, Madrid: Siglo XXI.

Engels, Friedrich (1884), "Marx y la Neue Rheinische Zeitung, 1848-1849", Der Sozialdemokrat, 13 de marzo, en Karl Marx y Friedrich Engels, Obras escogidas, Moscú: Editorial Progreso, 1974-1976, tomo III, pp. 174-183.

- (1885), Contribución a la historia de la Liga de los Comunistas, en Karl Marx y Friedrich Engels, Obras escogidas, Moscú: Editorial Progreso, 1974-1976, tomo III, pp. 184-202.

Hundt, Martin, Herwig Förder, Jefim Kandel y Sofia Lewiowa (eds.) (19701984), Der Bund der Kommunisten. Dokumente und Materialien, tomo 1: 1836-1849 (1970). Tomo 2: 1849-1851 (1982). Tomo 3: 1851-1852 (1984), Berlín: Dietz Verlag.

Hundt, Martin (1993), Geschichte des Bundes der Kommunisten 1836 bis 1852, Frankfurt: Peter Lang.

Lattek, Christine (2006), Revolutionary Refugees: German Socialism in Britain, 1840-1860, Londres-Nueva York: Routledge.

Marx, Karl (1847), Miseria de la filosofia: Respuesta a la filosofia de la miseria del señor Proudhon, México: Siglo XXI, 1987.

- (1848), "La burguesía y la contrarrevolución", Neue Rheinische Zeitung, ${ }^{\circ}$ 169, 11 de diciembre de 1848, en Karl Marx y Friedrich Engels, Obras escogidas, Moscú: Editorial Progreso, 1974-1976, tomo I, pp. 141-144.

- (1850a), Las luchas de clases en Francia de 1848 a 1850, en Karl Marx y Friedrich Engels, Obras escogidas, Moscú: Editorial Progreso, 19741976, tomo I, pp. 190-306.

- (1850b), "Erklärung an den Redakteur der Neue Deutsche Zeitung”, n 158 del 4 de julio de 1850, en Karl Marx y Friedrich Engels, Werke, Berlín: Dietz Verlag, 1973, 5. Auflage, tomo 7, pp. 323-324.

- (1852), "Carta a Joseph Weydemeyer en Nueva York" (Londres, 5 de mar- 
zo de 1852), en Karl Marx y Friedrich Engels, Obras escogidas, Moscú: Editorial Progreso, 1974-1976, tomo I, p. 542.

Marx, Karl y Friedrich Engels (1848), Manifiesto del Partido Comunista, en Karl Marx y Friedrich Engels, Obras escogidas, Moscú: Editorial Progreso, 1974-1976, tomo I, pp. 99-140.

Marx, Karl, y Friedrich Engels (1850), "Mensaje del Comité Central a la Liga de los Comunistas" (marzo de 1850), en Karl Marx y Friedrich Engels, Obras escogidas, Moscú: Editorial Progreso, 1974-1976, tomo I, pp. 179-189.

Marx, Karl, y Friedrich Engels (1965), Werke, Berlín: Dietz Verlag, tomo 27.

Marx, Karl y Friedrich Engels (1973), Werke, Berlín: Dietz Verlag, 5. Auflage, tomo 7.

Marx, Karl, Friedrich Engels, August Willich, Louis Adam, Jules Vidil, y George Julian Harney (1850), "Règlement de la Société Universelle des Communistes Révolutionnaires“, en Karl Marx y Friedrich Engels, Gesamtausgabe: Werke, Artikel, Entwürfe, Juli 1849 bis Juni 1851, 1977, 2 Bde.: Bd 10, Berlin: Akademie-Verlag.

Riazanov, David (1928), "Zur Frage des Verhältnisses von Marx zu Blanqui”, Unter dem Banner der Marxismus, año 2, pp. 140-149.

Weydemeyer, Joseph (1852), "The dictatorship of the proletariat", en TurnZeitung, Nueva York, 1 de enero de 1852, reprod. en Labor History, 1962, vol. $3, \mathrm{n}^{\circ} .2$, pp. 214-217. 